\title{
Is advertising ethical for dentists? An insight into the Indian scenario
}

This article was published in the following Dove Press journal:

Drug, Healthcare and Patient Safety

I5 December 20II

Number of times this article has been viewed

\author{
Rajani A Dable' \\ MA Prasanth ${ }^{2}$ \\ Shailendra B Singh' \\ Girish S Nazirkar' \\ 'Department of Prosthodontics, Sau \\ Mathurabai Bhausaheb Thorat (SMBT) \\ Dental College and Hospital, \\ Sangamner, Maharashtra, India; \\ ${ }^{2}$ Department of Pedodontics, \\ Vyas Dental College and Hospital, \\ Jodhpur, Rajasthan, India
}

Background: The question of whether Indian dentists should advertise their services is an important issue with significant ethical and professional implications. Individual dentists may feel the need to advertise in order to establish or grow a dental practice, but what effect does this have on the standing of the profession as a whole? As health care professionals are bound by a code of ethics, should dentists be allowed to advertise?

Purpose: The purpose of this study is to examine the attitudes of Indian dentists to the issue of advertising. It also aims to explore whether advertising could have positive benefits (to increase the community's awareness of dental health care, encourage better quality dental services, decrease unemployment in the industry, and help consumers choose a dentist), or, on the contrary, whether advertising could have a negative impact by undermining the reputation of the industry, in particular the definition of dentistry as a medical profession.

Methods: Of 1500 eligible participants, 423 dentists (28.2\%) participated in the study. The questionnaire, comprising 14 questions, was provided to the respondents. The data was collected and analyzed by applying the "Chi-squared test" of association and the " $\mathrm{Z}$ test" of difference between two proportions at $5 \%$ and $1 \%$ levels of significance (ie, $P=0.05$ and $P=0.01$ ).

Results: A majority of $56.02 \%$ of the respondents were in favor of dentists advertising their services. The majority of dentists in favor of advertising were in the youngest age group (22-30 years, $75.86 \%$ ). The older age groups were more likely to agree and comply with the government ban on advertising by dentists.

Conclusion: While Indian culture and law does not regard advertising as ethical, in recent years there has been a change in the attitudes of dental professionals to the issue of advertising.

Keywords: marketing, advertising, health care, ethics, law, dentistry, attitudes

\section{Introduction}

For health professionals in India, advertising has traditionally been seen as a controversial issue, and the notion of using advertising to promote a professional practice is relatively new. ${ }^{1}$ However, advertising by health care professionals in India has increased dramatically during the past decade, and this trend seems likely to continue, despite a government ban and even though many professionals find themselves ill equipped to handle the dynamics of this new and changing environment, especially without some form of marketing plan. ${ }^{2}$

In some countries, dentists have the right to advertise their practices within legal limits, but in India the rules against advertising by dentists are quite definite. In the Dentists (Code of Ethics) Regulations 1976, advertising, "whether directly or indirectly, 
for the purpose of obtaining patients or promoting his own professional advantage," (h) or "acquiescing in the publication of notice commending or directing attention to the practitioner's skills, knowledge, service or qualifications, or of being associated with or employed by those who procure or sanction such advertising or publication through press reports" (i) is defined as unethical, equal to the "conniving at or aiding in any kind of illegal practice" (f). ${ }^{3}$ Under the code of ethics, any advertisements by dentists should be limited to the announcement of the opening of a practice, a change of address, a change of ownership, or the introduction of a new associate or partner. ${ }^{3}$

Despite these rules, a number of practitioners ignore the code of ethics to advertise their services. Many dentists feel that advertising is a necessary part of running a business, and some argue that it has the potential to be beneficial. Supporters of advertising claim that informative advertising can empower consumers to make good decisions regarding their oral health; increase the community's awareness of dental health care; encourage better quality dental services by dental suppliers; decrease unemployment in the industry; and help consumers choose a dentist. However, there are also those who defend the traditional view that dentistry is primarily a health profession not a business, and that the ethical considerations of a practice should be paramount. Peltier defined the issue with a question - do dentists want to be doctors (serving the public) or merchants (small business entrepreneurs) $?^{4}$ There are certainly many opportunities for dentists to be either option, or even both. Yet, doctors and merchants live in very different ethical worlds, and they have very different roles and responsibilities in the community. ${ }^{4}$

Many dentists complain that industry competition has allowed a degree of commercialization to enter dentistry, which risks undermining the ethical standing of the profession. This commercialization is criticized as fostering inappropriate, misleading, and dishonest advertising. Its opponents object to the increased emphasis on fees (discounts, competition, and treatment "packages") and the encouragement of "dentist shopping," which induces dentists to regard patients as customers buying a service, rather than patients in need of help. ${ }^{5,6}$ Some dentists believe that advertising could have an adverse effect on the image of the profession in general and no impact on competitive price reduction. ${ }^{7}$

The dichotomy between the dual role of the dentist as a health care provider and as a business entity is at the heart of the issue of advertising. Commercial goals sit at one end of the spectrum, while patient care and professional goals weigh in on the other side. However, business itself is not unethical, and the reality is this: if the practice fails as a business, the practitioner fails as a medical professional.

\section{Traditional methods of marketing and managing a dental practice}

There are many strategies a dentist can employ to build a professional and commercially successful practice without breaking the law. Advertising is only one aspect of marketing, and every business owner should be aware of how to market their business, even if they cannot advertise. An advertisement is a paid promotion delivered via the media (print, television, radio), but marketing involves a systematic business plan that takes into consideration the business as a whole, including the ethics and culture of the company.

In India, many dentists use enticements, such as comparatively low fees, free check-ups, and complimentary gifts to attract patients. As with advertising, there is a risk that such methods could create a bad public impression and mar the reputation of the dentist. On the other hand, they may impress consumers, especially if quality treatment is provided with concessional or reasonable rates.

Dentists may also secure respect and a strong customer base by providing excellent customer service and demonstrating their clinical skills. A warm welcome, a pleasant atmosphere in a dentist's clinic, and the observation of simple etiquette, frequently results in relationships leading to maximum benefit. Establishing a good rapport with one's patients indirectly leads to what is possibly the only ethical advertising option: sincere recommendations by patients. In the past, a dentist's reputation was considered to be the major prerequisite for success in dentistry. While relying on promotion through the word-of-mouth referrals by patients takes time and must be secured through excellent service and skill, it can have long-term and ingrained benefits.

Communication is an important factor in the marketing and management process. Good communication can bring benefits to a practice, improving both patient and staff interest and expectations. ${ }^{8}$ Studies have shown that dentists should consider the use of internal communications, such as the practice brochure, business cards, in-house information centers, thank you notes, and direct mail to patients, ${ }^{9}$ as effective alternatives to advertising. The aim should be to communicate the clinic's services in a patient-specific, caring tone, rather than an impersonal message directed at a mass of consumers. ${ }^{10}$ With further study, dentists might conclude that radio, television, and newspaper advertisements are not 
as effective as internally generated communications, such as newsletters, press releases, and personalized letters. ${ }^{11}$

Health care relies on a relationship of trust between the medical professional and the patient. With this in mind, dental practitioners should consider their communication skills and ability to recognize the behavior processes of their patients as part of an overall management strategy. ${ }^{12}$ Trust can be developed on the basis of certain criteria, such as competence, promptness, reliability, ability to customize solutions, politeness, and empathy. ${ }^{12}$ When the factors that build trust are ignored, the practice will suffer. It is possible to see how trust cannot be instilled through advertising, but by a personalized approach based on the abilities and professionalism of the practitioner.

Interpersonal relationship plays an important role in the execution of dental services. A dentist should always be aware that the patient is always in the process of judging the dentists' interpersonal and clinical skills. ${ }^{13}$ Dentists do not have to become marketing mavens or understand the nuances of a well-placed advertisement, but they need to match their technical abilities with a good customer service to build a loyal base of patients and a successful practice.

\section{Material and methods}

A total of 423 respondents from throughout India participated in this study. Approximately 1500 questionnaires were distributed among dentists from eight metropolitan cities: Mumbai, Delhi, Bengaluru, Kolkata, Chennai, Hyderabad, Pune, and Nagpur; and also from the states of Jammu, Kashmir, Rajasthan, and Uttar Pradesh. The questionnaires were received at the end of 61 days and were submitted for analysis.
A comparative analysis of the attitudes of dentists toward advertising was carried out on the basis of their demographic characteristics. The questionnaire comprised 14 questions of which 11 questions were closed ended and three were based on a four-point Likert scale (Tables 1 and 2). These data were collected and analyzed by using statistical software, namely SYSTAT 12 (Cranes ${ }^{\circledR}$ Software International, Bangalore, India), and by applying the "Chi-squared test" of association, and the " $\mathrm{Z}$ test" of difference between two proportions at $5 \%$ and $1 \%$ level of significance (ie, $P=0.05$ and $P=0.01$ ).

\section{Results}

Tables 1 and 2 exhibit the responses given by dentists to questions asked in relation to the issue of advertising by health care professionals. A majority of $56.02 \%$ respondents did not believe that advertising by health professionals was unethical or unprofessional, and by inference disagreed with the government's ban; $43.97 \%$ respondents did regard the advertising of dental services as unethical. Respondents who approved of advertising gave various reasons as to why advertising should be or is used, but the majority (41.13\%) felt that advertising is best employed to develop a business, while $34.04 \%$ respondents stated that advertising is used to make people aware of good treatment services.

Many respondents (32.62\%) maintained that advertising would be beneficial for practicing dentists, as it would help them to communicate with the community. Some (26.24\%) were of the opinion that an abundance of specialty clinics has led to competition among dentists, and created a need to advertise. A smaller percentage of respondents (19.14\%) believed that the traditional referral system was no longer

Table I Highest percentage responses from dentists to specific research questions about advertising

\begin{tabular}{|c|c|c|}
\hline Questions & Reasons & $\begin{array}{l}\text { Highest } \\
\text { percentage }\end{array}$ \\
\hline I. In your view, is there a need for any form of advertising, and if so, why? & To advertise for good business & 41.13 \\
\hline 2. Do you consider advertising by health care professionals, unprofessional/unethical? & No & 56.02 \\
\hline 3. Do you think that advertising can benefit a dental practice? If so, how? & Easily reachable to community & 32.62 \\
\hline 4. Do you think that dental practitioners who do not advertise are disadvantaged? & $\begin{array}{l}\text { No, if a dentist believes in his/her } \\
\text { skills then advertising is not needed }\end{array}$ & 53.19 \\
\hline 5. Do you think that dental practices that do not advertise are seen as inferior? & No & 40.42 \\
\hline $\begin{array}{l}\text { 6. Advertising may make dentistry seem more like a trade than a health care service, } \\
\text { and this could be hazardous to the reputation of the dental profession. Please } \\
\text { give your opinion on this statement. }\end{array}$ & $\begin{array}{l}\text { It is hazardous, as health care services } \\
\text { cannot be advertised under Indian law }\end{array}$ & 26.95 \\
\hline $\begin{array}{l}\text { 7. Does the inclusion of dentistry in beauty centers pose a threat to the dental } \\
\text { profession? }\end{array}$ & $\begin{array}{l}\text { Yes, there is a risk that dentistry may become } \\
\text { limited to the cosmetic, rather than health care }\end{array}$ & 61.7 \\
\hline 8. Are misleading advertisements ethically acceptable? & No & 83.68 \\
\hline 9. Do you condone the use of global advertising and approve of dental tourism? & Yes & 51.06 \\
\hline $\begin{array}{l}\text { 10. If you do condone the use of global advertising and approve of dental tourism, } \\
\text { please state why. }\end{array}$ & $\begin{array}{l}\text { To ensure the cheapest and best } \\
\text { dental services }\end{array}$ & 35.46 \\
\hline II. Do you think that Indian dentists should stop using the title "Doctor"? & No & 89.36 \\
\hline
\end{tabular}


Table 2 Highest percentage responses from dentists to specific research questions about advertising, based on a four-point Likert scale

\begin{tabular}{lll}
\hline Questions & $\begin{array}{l}\text { Four-point } \\
\text { Likert scale }\end{array}$ & $\begin{array}{l}\text { Highest } \\
\text { percentage }\end{array}$ \\
\hline I. Do you agree with the & I. Agree & 36.87 \\
Indian government's ban on & 2. Strongly agree & 6.38 \\
advertising by health & 3. Disagree & 43.97 \\
care professionals? & 4. Strongly disagree & 12.05 \\
2. Can advertising and marketing & I. Agree & 48.22 \\
by dental professionals serve & 2. Strongly agree & 8.5 I \\
the community by ensuring better & 3. Disagree & 41.84 \\
quality services? & 4. Strongly disagree & 4.96 \\
3. Advertising by dental professionals & I. Agree & 29.78 \\
has the potential to degrade the & 2. Strongly agree & 7.09 \\
image of profession and undermine & 3. Disagree & 54.6 \\
its credibility. Do you agree? & 4. Strongly disagree & 7.09 \\
\hline
\end{tabular}

effective, as most people rely on media, such as newspapers, to find a dentist. Interestingly, only a few respondents $(7.8 \%)$ thought that advertising will augment the income of the dentist by attracting more patients.

A significant minority $(40.42 \%)$ thought that the practices of dentists who do not advertise would suffer because the general public would be unaware of their services, but the majority of respondents $(53.19 \%)$ disagreed with this assumption. Of the respondents, 53.19\% said that advertising does not have any effect on a dental practice. While $56.73 \%$ respondents were of opinion that advertising and marketing could serve the community by ensuring better quality services, $46.8 \%$ disagreed with this. Some opponents to advertising judged that advertising would lead to loss of credibility for the profession (36.87\%); yet, many more $(61.69 \%)$ argued this was unlikely.

In answer to the question, "Can advertising be hazardous to dentistry by turning it into a trade rather than a profession?", only $26.95 \%$ respondents agreed. More dentists were concerned about the current trend of incorporating cosmetic and aesthetic dentistry into beauty centers across

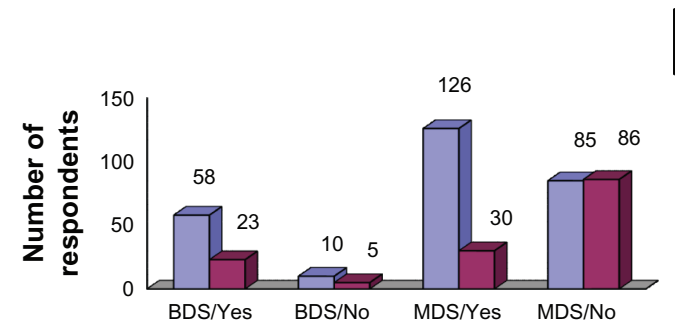

Figure I Gender distribution of dentists by qualification and attitude to advertising Yes/No responses to the question: Do you consider advertising by health care professionals, unprofessional/unethical?

Abbreviations: BDS, Bachelor of Dental Surgery; MDS, Masters of Dental Surgery. the country; $61.7 \%$ respondents mentioned that this development threatened the primary health care role of dentistry. Most respondents worried about the lack of sanitary conditions in beauty centers, and were concerned that patients might begin to confuse medical treatments with beauty treatments. Only $32.62 \%$ thought there was no harm involved because beauty centers regularly employ dentists as part of their treatment courses.

Nearly all dentists (83.68\%) were strongly opposed to advertisements such as "Get teeth in one day" or "Painless dentistry," which they regarded as unscientific and misleading. They demanded strict action be taken by the government against dentists who mislead consumers with such statements.

Global advertising has become very common in recent years. Of the respondents, 51.06\% complied with global advertising and dental tourism (26.24\% were opposed).

As per the current GDC proposal, the use of the term Doctor (or the abbreviation Dr) by Dentists should be limited to practitioners who have a $\mathrm{PhD}$ or who are medically qualified and registered Doctors. ${ }^{14}$ Indian dentists were asked if dentists should stop using the courtesy title of "Dr" (unless they have a $\mathrm{PhD}$ ): $89.36 \%$ respondents said that they regarded themselves as doctors who treat patients, and dentistry as a discipline of medicine and surgery, as the oral cavity and dentition are part of the body. The remaining $10.63 \%$ respondents thought Indian dentists should be referred to as "dentists" and not "doctors" (Tables 1 and 2).

\section{Comparative analysis as per demographic data}

The respondents were divided by age group: Group A (22-30 years); Group B (31-35 years); Group C (36-45 years); and Group D (over 46 years) (Table 3). The age analysis showed that the younger demographic are more in favor of

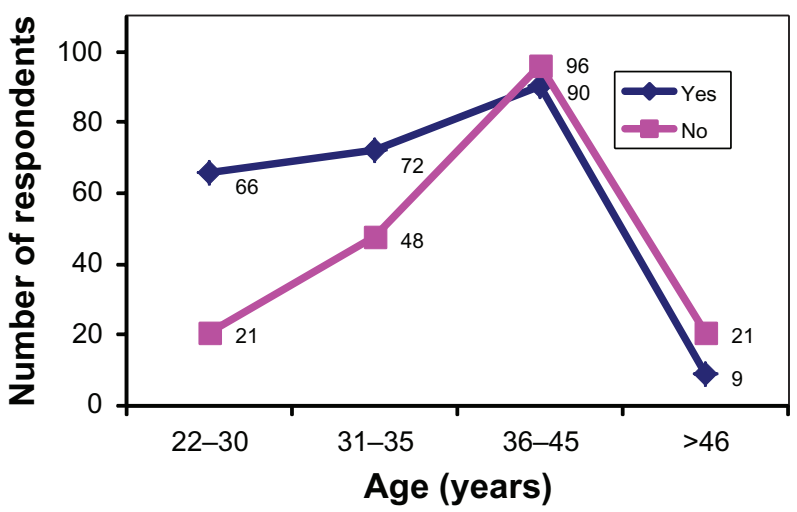

Figure 2 Age distribution of dentists by qualification and attitude to advertising. Yes/No responses to the question: Do you consider advertising by health care professionals, unprofessional/unethical? 
Table 3 Demographic characteristics of all of the dentists in the study

\begin{tabular}{|c|c|c|c|c|c|}
\hline \multirow[t]{2}{*}{ Characteristic } & \multirow{2}{*}{$\begin{array}{l}\text { Number of } \\
\text { respondents (\%) }\end{array}$} & \multicolumn{4}{|c|}{ Age range (\%) } \\
\hline & & $22-30$ years & $3 I-35$ years & $36-45$ years & $>45$ years \\
\hline Age & $423(100)$ & $20.57 \%$ & $28.37 \%$ & $43.97 \%$ & $7.09 \%$ \\
\hline MDS & $327(77.3)$ & $55.17 \%$ & $87.5 \%$ & $80.65 \%$ & $80 \%$ \\
\hline BDS & $96(22.7)$ & $44.82 \%$ & $12.5 \%$ & $19.35 \%$ & $20 \%$ \\
\hline Male & $279(65.96)$ & $72.41 \%$ & $52.5 \%$ & $67.74 \%$ & $90 \%$ \\
\hline Female & 144 (34.04) & $27.58 \%$ & $47.5 \%$ & $32.26 \%$ & $10 \%$ \\
\hline \multicolumn{6}{|c|}{ Advertising ethics } \\
\hline Ethical & $237(56.02)$ & $75.86 \%$ & $60 \%$ & $48.39 \%$ & $30 \%$ \\
\hline Unethical & $186(43.97)$ & $24.14 \%$ & $40 \%$ & $51.61 \%$ & $70 \%$ \\
\hline
\end{tabular}

Abbreviations: BDS, Bachelor of Dental Surgery; MDS, Masters of Dental Surgery.

advertising than their senior colleagues (Figure 2). Gender analysis demonstrated that men $(65.96 \%)$ are more in favor of advertising than women (34.04\%). By qualification, some $77 \%$ of respondents held a Masters of Dental Surgery (MDS); $65.82 \%$ responded in favor of advertising, but a firm $52.29 \%$ were in opposition. Of the 96 Bachelor of Dental Surgery (BDS) respondents, $84.37 \%$ favored advertising and $15.62 \%$ were against (Figure 1).

Application of the "Z test" shows a significant difference in the opinions of dentists regarding the government's ban on advertising. Using a four-point Likert scale, it is clearly demonstrated that most dentists believe advertising and marketing can serve the community with quality service, and that advertising does not lead to the loss of credibility of the dental profession $(P<0.05)$.

On applying the "Chi-squared test", it is seen that there is a highly significant association between age and qualification of the dentists under study $(P<0.01)$. For both genders, it can be observed that younger dentists and BDS-qualified dentists are more in favor of advertising than older dentists and MDS-qualified dentists.

\section{Discussion}

The present survey proves that more than half of the respondents $(56.02 \%)$ are in favor of advertising by dental professionals in India. Nonetheless, there are many who still consider advertising by health care professionals to be unethical. Most professionals and academics would be of the opinion that every health professional should know and follow an appropriate code of ethics. Although all Indian health universities include ethics in their syllabi, the subject is often overlooked or given secondary importance by institutions and academics.

Contrary to this there are a number of studies and surveys which favor advertising for various reasons. There are many who consider advertising necessary to build up and run their practices in a crowd of well-established dentists. Many of them are still trying to come to grips with the idea that advertising may be necessary to compete successfully. The internet, social networks and online sources have also changed the environment immensely; patients and dentists across the nation now use online testimonials and recommendations.

\section{Conclusion}

In spite of the ban on advertising by dentists, there are some who have resorted to some kind of advertising to promote their services. Unethical advertising is neither appreciated nor condoned, but there is a demand for relaxation in the restrictions, which would be beneficial in helping upcoming dentists to establish themselves in a competitive industry. An attitude change seems to be emerging in the upcoming generation of dentists, as the majority of younger dentists approve of advertising, while their seniors reject it. This may be a reflection of industry competition, a drop in ethical standards, or a greater familiarity with the world of advertising and media among younger age groups. The ethical objections to advertising by health care professionals, including dentists, persist with good cause. Advertising may be a force for good, but it could also undermine the health care role of dentistry. The rise of new technologies and media is another challenge, but the ethical issues remain the same.

\section{Acknowledgments}

The authors offer their sincere thanks to all of the dental practitioners across the country who kindly participated in this survey. The authors sincerely thank the institutional authority who granted them permission to conduct this study. The authors are also grateful to the statistician for his advice on statistical methods employed in this study, and to Professor Geetha N for her constructive help in editing this article. 


\section{Disclosure}

The authors report no conflicts of interest in this work.

\section{References}

1. Homer RM. How consumers view dental advertising: an empirical analysis. J Med Market. 2008;8(3):229-240.

2. Rizzo JA, Zeckhauser RJ. Advertising and the price, quantity, and quality of primary care physician services. J Hum Resour. 1992;27(3): 381-421.

3. Ministry of Health and Family Planning, Department of Health. Dentists (Code of Ethics) Regulations. Part II, Section 3, 6(h-o). New Delhi: The Gazette of India; 1976:2223-2227.

4. Peltier B. Codes and colleagues: is there support for universal patient acceptance? J Dent Educ. 2006;70(11):1221-1225.

5. Swiss P. Profit and principle. Dental Business. 1999;4:2-6.

6. Dummett CO. Ethics and bioethics in dentistry. $J$ Calif Dent Assoc. 1994;22(10):30-33.

7. Duffus LR. Physicians personally oppose Ads, but say it's ok to use them. Market News. 1990;24:19.
8. McGuigan PJ, Eisner AB. Marketing the dental practice: eight steps toward success. J Am Dent Assoc. 2006;137(10):1426-1433.

9. Nacht ES, Trupkin D. 15 internal marketing tools that will improve your practice of pediatric dentistry. J Clin Pediatr Dent. 1993;18(1): $1-2$.

10. Ashford RA. An investigation of male attitudes toward marketing communications from dental service providers. Br Dent J. 1998;184(5): 235-238.

11. Fields WT. Utilization, effectiveness and professional acceptability of marketing activities in dentistry. J Tenn Dent Assoc. 1988;68(1): 24-28.

12. Cole CA, Gaeth GJ. Cognitive and age-related differences in the ability to use nutritional information in a complex environment. J Market Res. 1990;27(2):175-184.

13. Bloom PN. Effective marketing for professional services. Harv Bus Rev. 1984;62(5):102-110.

14. Costley N, Fawcett J; General Dental Council. Patient and Public Attitudes to Standards for Dental Professionals, Ethical Guidance and Use of the Term Doctor. GDC: Public Attitudes Research Report. Edinburgh, UK: George Street Research; 2010.

\section{Publish your work in this journal}

Drug, Healthcare and Patient Safety is an international, peer-reviewed open-access journal exploring patient safety issues in the healthcare continuum from diagnostic and screening interventions through to treatment, drug therapy and surgery. The journal is characterized by the rapid reporting of reviews, original research, clinical, epidemiological and post-marketing surveillance studies, risk management, health literacy and educational programs across all areas of healthcare delivery. The manuscript management system is completely online and includes a very quick and fair peer-review system. Visit http://www.dovepress. com/testimonials.php to read real quotes from published authors. 